\title{
Visibilidad y alcance editorial de la Revista Argentina de Cardioangiología Intervencionista (RACI)
}

\author{
Visibility and editorial scope of the Argentine Journal of Interventional \\ Cardioangiology (RACl)
}

Revista Argentina de Cardioangiología Intervencionista 2018;9(4):194-194. DOI: 10.30567/RACI/201804/0194-0194

En este Editorial trataremos de analizar parcialmente la evolución de la Revista en los últimos tres años, desde julio de 2016 hasta el 6 de diciembre del corriente año.

Para ello utilizamos una plataforma especialmente diseñada y automatizada para lograr esta información, denominada "Google analytics" y que vamos a volcar en estas páginas.

Entre el 1 de julio de 2016 y el 6 de diciembre del 2018, ingresaron a la página web de RACI 9224 usuarios (personas individuales no repetidas) que accedieron 12854 veces a los contenidos, a razón de 1,4 vez por usuario.

Si tenemos en cuenta que entre socios activos y de la carrera de Especialista el CACI tiene alrededor de 620 miembros, está claro que el 93\% de los usuarios no son socios CACI ni integran nuestra sociedad, lo cual habla de la visibilidad que los articulos tienen fuera del ámbito estricto de nuestra especialidad.
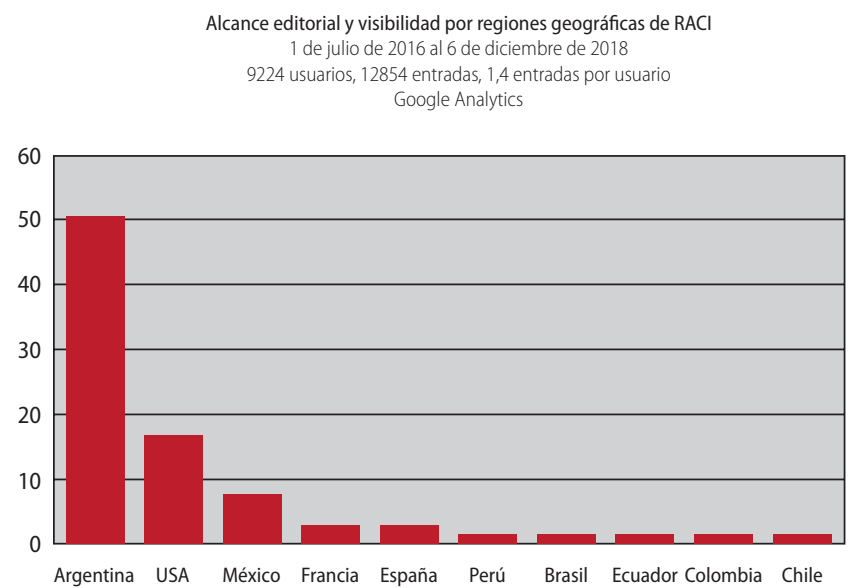

Figura 1.

En el año 2017 entraron a la página web 3439

usuarios, que accedierron 4878 veces a sus materiales, es decir, 1,4 por usuario.

El país de origen de los usuarios durante el año 2017 fue: Argentina en el 57,3\%, EE.UU. 12,5\%, México 8,4\%, España 3,1\%, Canadá 3,0\%, Brasil 2\%, etc.

Excluyendo la Argentina, el país de Sudamérica con mayor cantidad de usuarios fue Brasil, en el 6to lugar, mientras que en los primeros 5 observamos a países de América del Norte y Europa. Hallazgo que, debo decir, me sorprendió gratamente dada la importancia que tienen dichos países en la comunidad científica de nuestra especialidad.

En el año 2018, desde el 1 de enero hasta el 6 de diciembre, y aun faltando incluir el último número, la cifra de usuarios fue 4414, es decir un incremento con respecto al año anterior del 22\%, que ingresaron 5693 veces a razón de 1,3 vez por usuario, cifra que seguramente se elevará durante el mes de diciembre.

El origen geográfico de los usuarios fue: Argentina 44\%, EE.UU. 20,7\%, México 6,9\%, Francia 6,7\%, España 3,3\%, Ecuador 2,1\% y luego Colombia, Perú, Brasil y Chile entre el 2 y el 1.3\%.

Si revisamos el origen geográfico de los usuarios en todo este período julio 2016 a 6 de diciembre 2018 (Figura 1), los usuarios de Argentina fueron el 50,6\%, de EE.UU. el 17,2\%, México el 7,8\%, Francia 3,2\%, España 3,2\%, Perú 1,8\%, Brasil, Ecuador y Colombia en el 1,7\% y finalmente Chile en el 1,4\%.

Los motivos de las diferencias geográficas de los usuarios y el porcentaje por país pueden ser varios, pero sin duda aparece como muy importante que países como EE.UU. y/o de Europa estén interesados en nuestra Revista, dada la variedad de acceso en el conocimiento que tienen los mismos y el alcance masivo editorial de los mayores journals del EE.UU. y Europa.

Teniendo en cuenta el número de usuarios argentinos que para el período fue $50.6 \%$, debemos decir que el $86,7 \%$ de los mismos no son socios de nuestra sociedad científica.

Esto último debemos tenerlo en cuenta al momento de analizar el alcance editorial de RACI fuera de los "edges" de la Cardiología Intervencionista y que debiera estimular a todos nuestros jóvenes staff y fellows a priorizar la revista RACI al momento de la publicación de un artículo original. 